\title{
İmplant ile ilişkili osteomiyelitin önlenmesinde bor katkılı nano-hidroksiapatit kompozit uygulamaları
}

\author{
Boron containing nano-hydroxyapatite composite applications \\ for implant related osteomyelitis prevention
}

\author{
Eda Çiftci Dede ${ }^{1}$, Merve Gizer², Petek Korkusuz ${ }^{3}$, Feza Korkusuz ${ }^{4}$
}

\author{
${ }^{1}$ Hacettepe Üniversitesi Fen Bilimleri Enstitüsü, Biyomühendislik Anabilim Dalı, Ankara \\ ${ }^{2}$ Hacettepe Üniversitesi Sağlık Bilimleri Enstitüsü, Kök Hücre Bilimleri Anabilim Dalı, Ankara \\ ${ }^{3}$ Hacettepe Üniversitesi Tıp Fakültesi, Histoloji ve Embriyoloji Anabilim Dalı, Sıhhiye, Ankara \\ ${ }^{4}$ Hacettepe Üniversitesi Tıp Fakültesi, Spor Hekimliği Anabilim Dalı, Sıhhiye, Ankara
}

\begin{abstract}
İmplant ilişkili enfeksiyonlar en sık rastlanan kas-iskelet sistemi enfeksiyonlarıdır. Enfeksiyon, genellikle travma sonrası oluşan kırıklarla veya ameliyat sonrasında gelişmektedir. Mikroorganizmaların kontaminasyonu sonucunda kemik ve eklemde odak enfeksiyon noktası oluşabilmekte ve kan yoluyla dağılım gösterebilmektedir. Patojenlerin implant yüzeyinde biyofilm oluşturması ise antibiyotiğe karşı direncin gelişmesine ve dolayısıyla tedavide farklı yaklaşımların gerekliliğine neden olmaktadır. Hidroksiapatit, kemiğin hücre dışı matriksinin amorf kristal yapılı, inorganik ana bileşenidir. Yüksek osteokondüktif özelliğinden dolayı kemik ile implant arasındaki tutunumunu artırmak amacıyla implantlarda yüzey kaplamaları olarak yaygın kullanılmaktadır. Çeşitli ilaçlar, büyüme faktörleri, polimerler ve mineraller ile hidroksiapatitlere farklı özellikler (antibakteriyellik, osteoindüktiflik, yüksek direnç vb.) kazandırılabilmektedir. Bor doğada borik asit ve borat gibi farklı formlarda bulunabilen bir mineral çeşididir. Borun antibakteriyel özelliği bulunduğu bilinmektedir. Antibakteriyel özellikli borun, osteokondüktif özellikte olan nanometre boyutundaki hidroksiapatit kristalleriyle beraber implant üretim aşamalarında kullanılması sayesinde implant ilişkili enfeksiyonların hedeflenebileceği ve önüne geçilebileceği düşünülebilir. Bu derlemede bor ve hidroksiapatitin implant ilişkili enfeksiyonlara karşı uygulandığı çalışmalar özetlenmiştir.
\end{abstract}

Anahtar sözcükler: implant ilişkili enfeksiyonlar; kas-iskelet sistemi enfeksiyonları; hidroksiapatit; bor
Implant related infections are the most common musculoskeletal system infections. Infection usually comprises with a post-traumatic fractures or after surgery. As a result of contamination of microorganisms, a focal infection point may occur in the bone and joint and it can be distributed through the blood. The formation of biofilms on the implant surface causes the consist of resistance against antibiotics and therefore the necessity of different approaches in treatment. Hydroxyapatite is the amorphous crystalline main inorganic component of the extracellular matrix of bone. Due to their high osteoconductive properties, they are widely used as surface coatings in implants in order to increase bone-implant adhesion. Different properties (antibacteriality, osteoinductivity, strength, etc.) can be added to hydroxyapatite by various drugs, growth factors, polymers, and minerals. Boron is a type of mineral that can be found in different forms such as boric acid and borate in nature. It is known that boron has antibacterial properties. It can be considered that implant-related infections can be targeted and prevented by using the antibacterial boron with the nanometer-sized hydroxyapatite crystals that are osteoconductive materials, in implant production stages. In this review, the studies in which boron and hydroxyapatite are applied against implant related infections are summarized.

Key words: implant related infections; musculoskeletal infections; hydroxyapatite; boron
K as-iskelet enfeksiyonları mikroorganizmaların kontaminasyonu sonucunda kemik, eklem veya çevre dokularda gelişen ve kan yoluyla yayılım gösteren, sıkça karşılaşılan bir sağlık sorunudur. Kas-iskelet sistemi kapsamında kemikte osteomiyelit, eklemde septik artrit ve tüm sistemde implant ilişkili enfeksiyonlar en sık rastlanan hastalıklardır. Osteomiyelit, akut ve kronik olarak seyredebilmekte ve ana enfeksiyon bölgesinden komşu bölgelere, vasküler yetersizlik veya kan yolu ile yayılım göstermektedir. ${ }^{[1,2]}$ Akut osteomiyelit sekestrum ile sonuçlanan devaskülarizasyon nedeniyle hızlıca kronik

- Illetişim adresi: Prof. Dr. Feza Korkusuz, Hacettepe Üniversitesi Tıp Fakültesi, Spor Hekimliği Anabilim Dalı, Sıhhiye, Ankara Tel: 0312 - 3051347 e-posta: feza.korkusuz@hacettepe.edu.tr

- Geliștarihi: 3 Haziran $2020 \quad$ Kabul tarihi: 17 Haziran 2020 
osteomiyelite gelişebilmektedir. Gelişen sekestrum, enfeksiyon bölgesine antibiyotiklerin ulaşımını engelleyerek kronik osteomiyelitin tedavisini geciktirmekte ve kemik defektinin büyümesine neden olmaktadır. Septik artrit, kan yolu ile yayılan enfeksiyon sonucunda eklemlerde gelişmektedir. Osteomiyelit ve septik artrit genellikle Staphylococcus aureus (S.aureus), metisilin dirençli Staphylococcus aureus (MDSA) ve Staphylococcus epidermidis (S.epidermidis) enfeksiyonları sonucunda oluşmaktadır. İmplant ilişkili enfeksiyonlar ise çoğunlukla S.aureus, S.epidermidis ve Escherichia coli (E.coli) tür bakterilerin kontaminasyonu ve biyofilm oluşturmaları sonucunda gerçekleşmektedir. ${ }^{[1]}$

Hidroksiapatit (HAp), kemiğin ekstrasellüler matriksinin (ESM) inorganik ana bileşenidir. Hidroksiapatit kemiğin yapısında bulunması nedeniyle sentetik olarak üretilmekte ve kemik rejenerasyonunu hedefleyen ortopedik biyomalzeme uygulamalarında yüksek osteokondüktif etkisi nedeniyle klinikte kullanılmaktadır. ${ }^{[3,4]}$ Kalsiyum fosfat temelli bir biyomalzeme tipi olan HAp, biyoseramik alt sınıfına girmekte ve $3 \mathrm{~nm}$ ile $2000 \mu \mathrm{m}$ boyutları arasında üretilebilmektedir. Üretim boyutu, HAp'in fiziksel ve fonksiyonel özelliklerini etkilemektedir. Nanometre boyutunda üretilen HAp'in yüzey alanının artması nedeniyle biyoaktif özellikleri artmaktadır ve mikrometre boyutundaki HAp'e kıyasla daha yüksek mekanik dayanımı olduğu, düşük doku cevabı oluşturduğu ve mineralizasyon ile osteointegrasyonu artırdığı bildirilmiştir. ${ }^{[3,5]}$ Nanometre boyutunda HAp (nHAp) antibiyotik taşıma sistemlerinde de kullanılmaktadır. ${ }^{[3,6]}$ Nanometre boyutunda HAp'in biyoaktifliği hedeflenen amaç doğrultusunda magnezyum ve çinko gibi iz elementler ile artırılabilmektedir. ${ }^{[7]}$ Bir diğer iz element bor (B), nHAp ile beraber kullanıldığında kemik rejenerasyonunun uyarılmasına katkıda bulunmaktadır. ${ }^{[8,9]}$ Kemikteki rejeneratif kapasitesinin yanı sıra, antibakteriyel özellikleri ile B, nHAp'nin antimikrobiyal aktivitesini artırabilir ve böylece implant ilişkili enfeksiyonların önlenmesine destek olabilir. Bu kapsamda implant ilişkili enfeksiyona ve gelişimine karşı B ve nHAp kullanıldığı çalışmalar özetlenecektir.

\section{IMPLANT ILIŞKILI ENFEKSIYONLAR}

İmplant ilişkili enfeksiyonlar ortamda bulunan bakterilerin ameliyat sırasında, açık kırıklar sonucunda veya firsatçı bakterilerin immun sistemi zayıflatması nedeniyle implant yüzeyine adhere olması (yapışması) ile başlamakta ve adhere olan bakterilerin implant yüzeyi ile konakçı dokusu arasında biyofilm oluşturması ile gelişmektedir. İmplant ilişkili enfeksiyonlar erken, gecikmiş ve geç enfeksiyon olmak üzere üç sınıfa ayrılmakta ve gram pozitif S.aureus, S.epidermidis ve gram negatif E.coli patojen kaynağını oluşturmaktadır. ${ }^{[7,10]}$ S.aureus internal ve eksternal fiksatiflerde, S.epidermidis ise diz ve kalça implantlarında enfeksiyon oluşturmaktadır. ${ }^{[11]}$ İmplant ilişkili enfeksiyonların \%65'ine S.aureus ve S.epidermidis neden olmaktadır. ${ }^{[12]}$

Staphylococcus aerobik, gram pozitif kok tipi bakterilerdir. Staphylococcus fakültatif aerobik olması nedeniyle hem normoksik hem de hipoksik koşullarda glikozu kullanabilmektedir. Hücre duvarında teikoik asit içermektedir. Escherichia fakültatif aerobik, gram negatif çubuk tipi bakterilerdir. ${ }^{[13]}$ İmplant ilişkili enfeksiyon patojenleri olan S.aureus, S.epidermidis, MDSA ve E.coli biyofilm yapısı oluşturarak antibiyotik direnci göstermekte ve akut enfeksiyonun kronik enfeksiyona dönüşmesine ve yayılımına neden olmaktadır. ${ }^{[4]}$ Biyofilm oluşumu Şekil 1'de şematize edilmiştir.

İmplant yüzeyine adhere olarak kolonileşen mikroorganizmalar sessil tip; asılı şekilde kolonileşen mikroorganizmalar ise planktonik tip olarak sınıflandırılmaktadır. Biyofilm bakteriyel adhezyona göre iki aşamada gerçekleşmektedir. Bu aşamalar; başlangıç aşaması, geri döndürülebilir fiziksel aşama ve zaman bağımlı geri döndürülemez moleküler aşamadır. ${ }^{[12,14]}$ Bakteri ilk olarak geri döndürülebilir spesifik olmayan tutunma ile implant yüzeyi ile etkileşime geçmekte ve bunu spesifik ve geri döndürülemez tutunma takip etmektedir. ${ }^{[14]}$ İmplant doku etkileşim seviyesi nano boyuttan makro boyuta, nanosaniyelerden günlere kadar sürmektedir. Bu etkileşim su-implant yüzey etkileşimi ile başlamakta, saniyeler içinde ESM proteinlerinin implant yüzeyine adsorpsiyonu ile devam etmektedir. Bu aşamada adsorbe olan proteinler bakteriyel adhezyonu da artıracak etkide bulunmaktadır. ${ }^{[15]}$

İmplant yüzeyine planktonik tip bakteri hidrofobik, van der Waals ve Lewis kuvvetleri ile spesifik olmayan biçimde yönlendirilmektedir. Bu yönlendirme, bakterinin implant yüzeyine tutunması ve adhezyonu ile devam etmektedir. Bakterinin adhezyonu pili, kapsül ve plis-benzeri yapılar ile gerçekleşmektedir. ${ }^{[16]}$ Bakterinin ekstrasellüler alana salgıladığı polisakkarit, lipid ve ekstrasellüler DNA (eDNA), adhezyonu artırmaktadır (Şekil 1). Bakterinin salgıladığı bu yapı ekstrasellüler polimerik maddeyi (EPM) oluşturmaktadır. Bakteriler salgıladıkları EPM içinde hapsolarak dış çevrenin etkisinden korunmaktadır. Bakteri bu alanda EPM ile birlikte biyofilm tabakasını oluşturmaktadır. Biyofilm tabakası bakterinin antibiyotik direncini artırmaktadır. ${ }^{[11]}$ Adhezyon çevrenin $\mathrm{pH}^{\prime} ı$ indan, sıcaklığından, akış koşullarından ve implant özelliklerinden etkilenmektedir. İmplantın yüzey kimyası ve topolojisi 


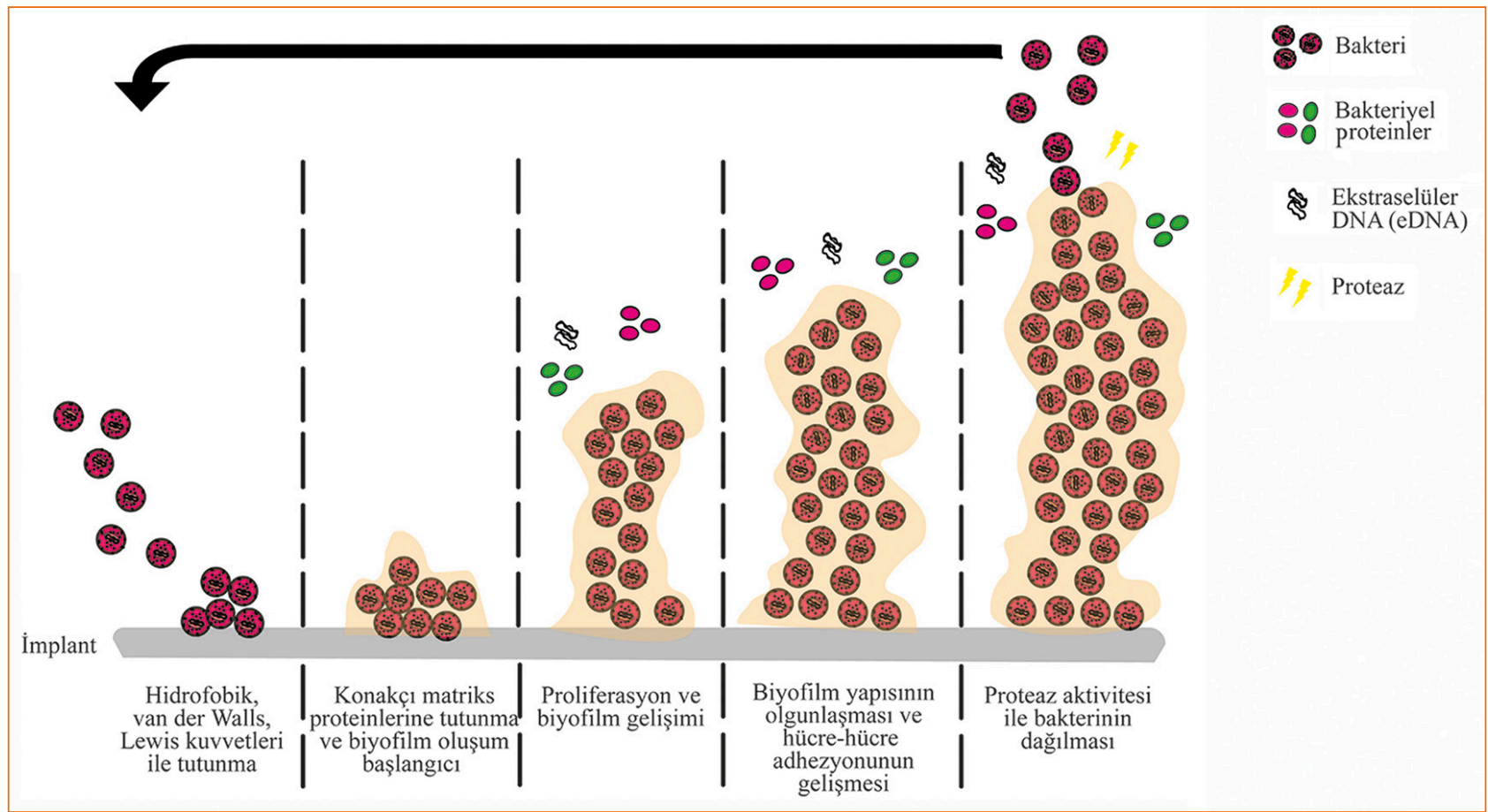

Şekil 1. Biyofilm oluşumu şematize edilmiştir.

bakterinin adhezyonu ile proliferasyonunu etkilemekte bu nedenle farklı kompozitler kullanılarak adhezyonun hiç gerçekleşmemesi ve biyofilm oluşumunun engellenmesi hedeflenmektedir. ${ }^{[12,14]}$

\section{BOR KATKILI NANO-HIDROKSIAPATIT KOMPOZITLER VE IMPLANT ILIŞKILI ENFEKSIYONLARDA UYGULAMALARI}

\section{Nano-Hidroksiapatit ve İmplant ilişkili Enfeksiyonlar}

Hidroksiapatitler, kemiğin inorganik yapısını oluşturan, ortopedik uygulamalarda, kemik yerine geçebilen ve kemiği yenileme kapasitesi olan biyo-uyumlu malzemelerdir. Hidroksiapatit kaplı yüzeyde kemik iliği kaynaklı mezenkimal kök hücrelerin tutunarak çoğaldıkları Şekil 2'de görülmektedir. Biyo-uyumluluklarının yanı sıra, anti-enflamatuvar, osteokondüktif ve biyobozunabilir olmaları kalsiyum fosfatlar arasında ilgi çekmelerine neden olmuştur. ${ }^{[3,4]} \mathrm{Bu}$ avantajların yanı sıra, HAp seramiklerinin kırılganlık ve elastiklik özelliğinin olmaması gibi dezavantajları, çeşitli malzemelerin, yapılarına katılması ile aşılabilmektedir. HAp'lerin klinik kullanımı, kemik rejenerasyonu ve implant entegrasyonunu amaçlar. Kemiğin doğal yapısında HAp nano boyutlu olarak bulunmaktadır ve sentetik olarak da elde edilebilmektedir. ${ }^{[3]}$

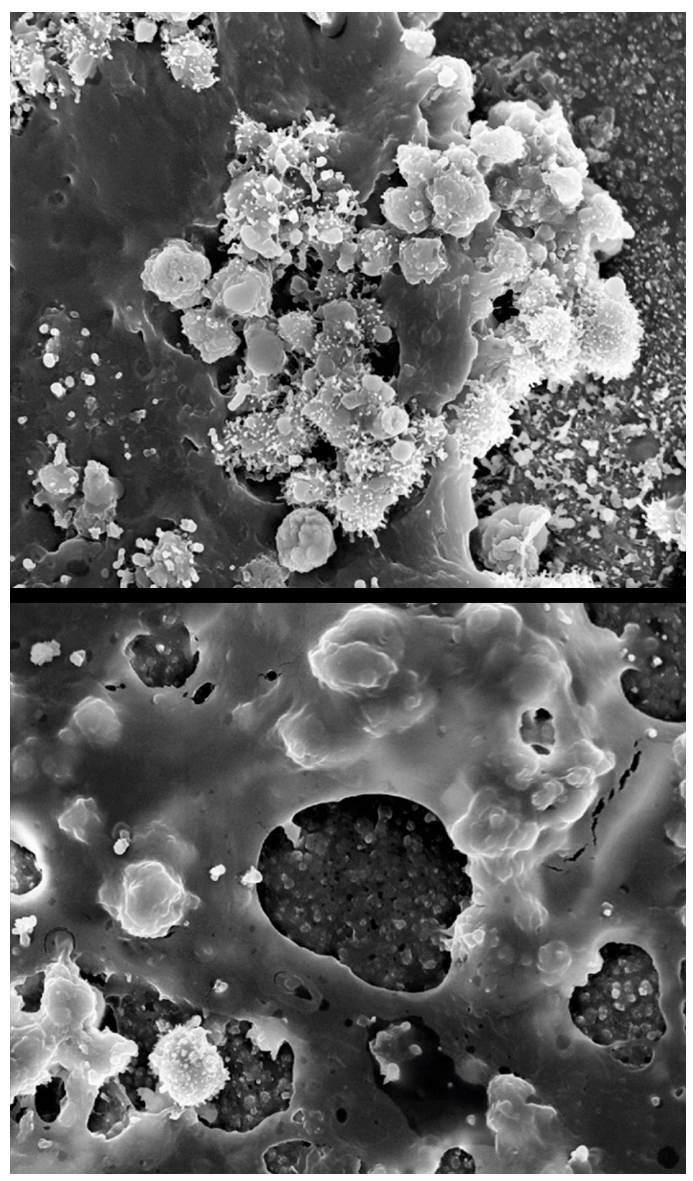

Şekil 2. İnsan kemik iliği kaynaklı mezenkimal kök hücrelerin hidroksiapatit yüzeye tutundukları taramalı elektron mikrograflarında görülmektedir (15000×). 
Hidroksiapatit kaplamalar kendi başına implantlarda antimikrobiyal etkinlik gösterememektedirler. Bu nedenle çeşitli antimikrobiyal ajanlarla beraber kullanılabilirler. Tablo 1'de HAp'lerin antimikrobiyal ajanlar ile beraber kullanıldıkları çalışmalar özetlenmiştir.

\section{Bor Katkılı Nano-Hidroksiapatit ve İmplant ilişkili Enfeksiyonlar}

Bor doğada borik asit (BA) ya da borat formlarında bulunan bir mineraldir. Sıçanlar üzerinde yapılmış borun kemiğe olan etkilerinin değerlendirildiği çalışmalar$\mathrm{da}$, borun kemik mineral yoğunluğunu olumlu yönde etkilediği, D vitamini metabolizmasını dengelediği, diyet yolu ile uygulandığında kemiğin mekanik kuvvetini ve dayanımını artırdığı, bölgesel uygulamalarda ise yeni kemik oluşumunu desteklediği bildirilmiştir. ${ }^{[23]}$ Klinik çalışmalarda, bor uygulamasının menopoz sonrası kadınların serumlarındaki osteokalsin seviyesini artırdığı sonucu elde edilmiştir. ${ }^{[24]}$ Borun kemikler üzerindeki olumlu etkileri dışında, antibakteriyel özellikleri olduğu bilinmektedir. Yapılan çalışmalarda borun çeşitli türevlerinin, S.aureus, E.coli, Acinetobacter septicus (A.septicus) ve Pseudomonas aeruginosa (P.aeruginosa) bakteri gruplarına karşı aktivitesi değerlendirilmiştir. Çalışmalarda S.aureus ve A.septicus'un bor bileşiklerine E.coli ve P.aeruginosa'dan daha duyarlı oldukları, bor tarafindan biyofilmlerin inhibe edildikleri sonucuna varılmıştır. Çalışmaların sonucunda borik asidin minimum inhibitör konsantrasyonunun (MiK) 0,77-7,60 $\mathrm{mg} / \mathrm{mL}$ doz aralığında olduğu, boratın MiK değerinin $23,80-47,60 \mathrm{mg} / \mathrm{mL}$ doz aralığında olduğu ve disodyum oktaborat tetrahidratın (DOT'nin) ise 0,644-10,312 $\mathrm{mg} / \mathrm{mL}$ doz aralığında olduğu bildirilmiştir. ${ }^{[25,26]}$ Kemik iliği ve çevresinde oluşan bir kemik enfeksiyonu hastalığı olan, osteomiyelitin tedavisinde borun ve antibiyotik tedavisinin beraber çalışıldığı sayılı çalışma bulunmaktadır. Vankomisin yüklü borlu biyoaktif camların osteomiyelit tedavisinde kullanımının araştırıldığı iki çalışmada, MDSA ile indüklenmiş osteomiyelitin yüksek oranda (\%80'in üzerinde) iyileşme gösterdiği, kemiğe uygulanan bu vankomisin taşıyıcı borlu biyoaktif camların aynı zamanda yeni kemik oluşumunu da desteklediği bildirilmiştir. ${ }^{[27,28]}$ Başka bir çalışmada sıçan tibiasında geliştirilmiş olan osteomiyelit modelinde lokal ve sistemik olarak borik asit ve vankomisin uygulanmış, çalışma sonucunda borik asitin osteomiyeliti tedavi ettiği ancak vankomisin ile etkinliğinin arttığı tespit edilmiştir. ${ }^{[29]}$ Teikoplanin yüklü biyoaktif borat cam ve kalsiyum sülfatın aktivitesinin MDSA ile indüklenen osteomiyelit tavşan modelinde değerlendirildiği başka bir çalışmada ise biyoaktif borat camın, kalsiyum sülfat kompozitine kıyasla, teikoplaninin lokal uygulanması için daha uygun olduğu bildirilmiştir. ${ }^{[30]}$

Tablo 1. Hidroksiapatitin implant ilişkili enfeksiyon araştırmalarında kullanıldığı çalışmalar

\begin{tabular}{|c|c|c|c|}
\hline Malzeme & Çalışma Modeli & Etki & Kaynak \\
\hline $\mathrm{Ag}-\mathrm{HAp}$ & $\begin{array}{l}\text { S.aureus ve P.aeruginosa üzerinde antibakteriyel } \\
\text { özellikler değerlendirilmiştir. }\end{array}$ & $\begin{array}{l}\text { Plazma püskürtme yöntemi ile uygulanan Ag katkılı } \\
\text { HAp kaplamalar, kaplamaların mekanik özelliklerini } \\
\text { değiştirmeden etkin antibakteriyel özelliklere sahip } \\
\text { olabildikleri, in vitro ve in vivo iyi biyo-uyumluluk } \\
\text { gösterdiği bildirilmiştir. }\end{array}$ & {$[17,18]$} \\
\hline $\mathrm{Ag}, \mathrm{Sr}-\mathrm{HAp}$ & $\begin{array}{l}\text { Titanyum üzerine hidrotermal yöntemle } \\
\text { Ag eklenmiş HAp kaplamalarına Ag'nin } \\
\text { sitotoksisitesini Sr ilave edilerek antimikrobiyal } \\
\text { özellikler değerlendirilmiştir. }\end{array}$ & $\begin{array}{l}\text { Ag ve Sr katkılı hidrotermal olarak çökeltilmiş HAp } \\
\text { kaplamaların etkin biyo-uyumluluk ve antimikrobiyal } \\
\text { aktivite sergiledikleri, bu tür kombine katkılı HAp } \\
\text { kaplamaların ortopedik implant modifikasyonu } \\
\text { potansiyeli olduğu bildirilmiştir. }\end{array}$ & [19] \\
\hline $\mathrm{Ag}, \mathrm{Si}-\mathrm{HAp}$ & $\begin{array}{l}\text { S.aureus ve E.coli bakterilerinin Ag, Si-HAp'a } \\
\text { biyolojik yanıt ve antimikrobiyal özellikleri } \\
\text { incelenmiştir. }\end{array}$ & $\begin{array}{l}\text { Ag ve Si'nin HAp yapısına katılmasının, kaplamaya } \\
\text { antibakteriyel özellik kazandırdığı ve biyo- } \\
\text { uyumluluğu artırarak tamamlayıcı etki yaptığı } \\
\text { bildirilmiştir. }\end{array}$ & {$[20]$} \\
\hline $\begin{array}{l}\text { Ultra-yüksek moleküler } \\
\text { ağırlıklı polietilen, HAp }\end{array}$ & $\begin{array}{l}\text { Klinik çalışma -klinik olarak yapışan } \\
\text { mikroorganizmaların miktarının malzeme veya } \\
\text { bileşenle ilgisinin tayini için enfekte olmuş eklem } \\
\text { replasmanları incelenmiştir. }\end{array}$ & $\begin{array}{l}\text { Bakteriyel yapışmanın öncelikle enfektif } \\
\text { mikroorganizmaya ve her bir hastanın malzemeye } \\
\text { yanıtına bağlı olduğu bildirilmiştir. }\end{array}$ & {$[21]$} \\
\hline PLGA-Gentamisin-HAp & $\begin{array}{l}\text { PLGA-Gentamisin-HAp -kaplamanın farklı } \\
\text { in vitro modellerde antibiyotik salınımının } \\
\text { ve antibakteriyel özelliklerinin ve tavşanlarda } \\
\text { implantla ilişkili enfeksiyonun önlenmesindeki } \\
\text { etkinliğinin değerlendirilmesi incelenmiştir. }\end{array}$ & $\begin{array}{l}\text { PLGA-gentamisin-HAp kaplamaların çimentosuz } \\
\text { protezlerde enfeksiyon profilaksisi için etkili bir } \\
\text { strateji oluşturduğu bildirilmiştir. }\end{array}$ & {$[22]$} \\
\hline
\end{tabular}

HAp, hidroksiapatit; S.aureus, Staphylococcus aureus; P.aeruginosa, Pseudomonas aeruginosa; E.coli, Escherichia coli; PLGA, poli laktik-ko-glikolik asit. 


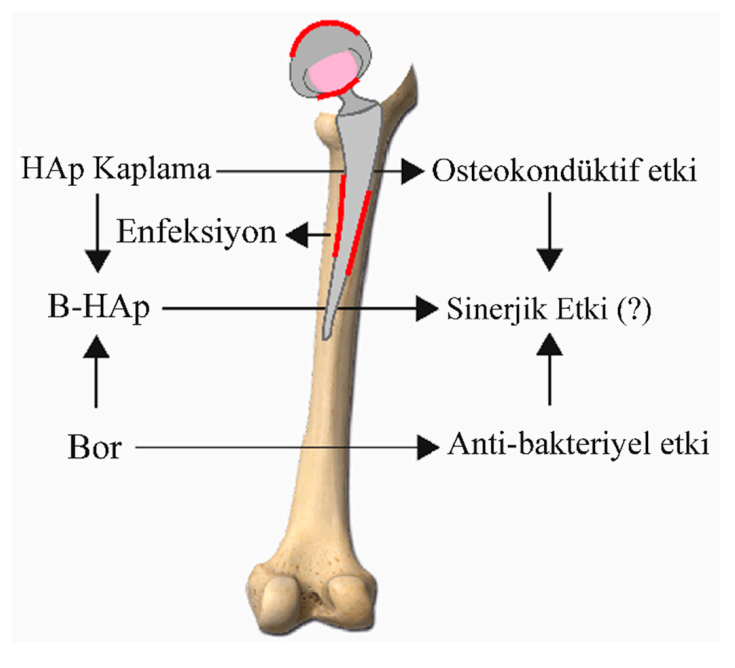

Şekil 3. İmplant ilişkili enfeksiyonlarda HAp ve borun etkileri şematize edilmiştir (B-HAp, bor katkılı hidroksiapatit; HAp, hidroksiapatit).

Bor katkılı HAp kompozitlerin kemik rejenerasyon çalışmaları bulunmasına rağmen, enfeksiyon araştırmasında kullanıldıkları bir çalışmaya literatürde rastlanmamıştır ancak sadece HAp ya da sadece B'nin değerlendirildiği çalışmalar ışığında, HAp'lerin uygun dozda B ile beraber implant yapısına katılması sayesinde, implant ilişkili enfeksiyonları engelleyebilecek bir yöntem geliş̧irilebilir.

\section{SONUÇ}

Klinikte sıklıkla rastlanan osteomiyelit, eklemde septik artrit ve tüm sistemde implant-ilişkili enfeksiyonlar, mikroorganizmaların yayılımı sonucunda kemik, eklem veya çevre dokularda gelişen ve kan yoluyla yayılım gösteren hastalıklardır. Kemiğin inorganik yapısında bulunan HAp seramikler özellikle implant kaplamalarda kemiğin, implanta tutunumunu artırmak için kullanılmaktadır. Bu kaplamalar tek başına anti-bakteriyel etki gösteremediklerinden, çeşitli anti-bakteriyel etkili mineraller ya da ilaçların yapılarına katılması ile bu özellikleri kazanabilirler. Bor türevlerinin osteomiyelit tedavisinde olumlu sonuçlar gösterdiği çalışmalar bulunmaktadır. Hidroksiapatitin ve B türevlerinin kemik ve enfeksiyonları üzerine etkileri Şekil 3'te şematize edilmiştir. Borun, HAp ile beraber enfeksiyon araştırmalarında kullanıldığı herhangi bir çalışma bulunmamasına rağmen beraber kullanılmaları implant ilişkili enfeksiyonların engellenebilmesi için umut vaat edici olabilir.

\section{KAYNAKLAR}

1. Birt MC, Anderson DW, Toby EB, Wang J. Osteomyelitis: Recent advances in pathophysiology and therapeutic strategies. J Orthop 2017;14(1):45-52. Crossref

2. Maffulli N, Papalia R, Zampogna B, Torre G, Albo E, Denaro $V$. The management of osteomyelitis in the adult. Surgeon 2016;14(6):345-60. Crossref

3. Kankilic B, Dede EC, Korkusuz P, Timuçin M, Korkusuz F. Apatites for orthopedic applications (Chap. 3). In: Kaur $G$, editor. Clinical Applications of Biomaterials. Springer International Publishing AG ${ }^{\odot}$; 2017. p. 65-90. Crossref

4. Kose S, Kankilic B, Gizer M, Ciftci Dede E, Bayramli E, Korkusuz P, Korkusuz F. Stem Cell and Advanced Nano Bioceramic Interactions. Adv Exp Med Biol 2018;1077:31742. Crossref

5. Korkusuz F, Timuçin M, Korkusuz P. Nanocrystalline ApatiteBased Biomaterials and Stem Cells in Orthopaedics. In: Ben-Nissan B, editor. Advances in Calcium Phosphate Biomaterials. Berlin, Heidelberg: Springer Berlin Heidelberg; 2014. p. 373-90.

6. Korkusuz F, Uchida A, Shinto Y, Araki N, Inoue K, Ono K. Experimental implant-related osteomyelitis treated by antibiotic-calcium hydroxyapatite ceramic composites. J Bone Joint Surg Br 1993;75-B(1):111-4. Crossref

7. Trampuz A, Zimmerli W. Diagnosis and treatment of implantassociated septic arthritis and osteomyelitis. Curr Infect Dis Rep 2008;10(5):394-403. Crossref

8. Ciftci E, Köse S, Korkusuz P, Timuçin M, Korkusuz F. Boron Containing Nano Hydroxyapatites (Bn-HAp) Stimulate Mesenchymal Stem Cell Adhesion, Proliferation and Differentiation. Key Eng Mater 2014;631:373-8. Crossref

9. Gizer M, Köse S, Karaosmanoglu B, Taskiran EZ, Berkkan A, Timuçin M, Korkusuz F, Korkusuz P. The Effect of BoronContaining Nano-Hydroxyapatite on Bone Cells. Biol Trace Elem Res 2020;193(2):364-76. Crossref

10. Sampath Kumar TS, Madhumathi K, Rubaiya Y, Doble M. Dual mode antibacterial activity of ion substituted calcium phosphate nanocarriers for bone infections. Front Bioeng Biotechnol 2015;3:59. Crossref

11. Oliveira WF, Silva PMS, Silva RCS, Silva GMM, Machado G, Coelho LCBB, Correia MTS. Staphylococcus aureus and Staphylococcus epidermidis infections on implants. J Hosp Infect 2018;98(2):111-7. Crossref

12. Ribeiro M, Monteiro FJ, Ferraz MP. Infection of orthopedic implants with emphasis on bacterial adhesion process and techniques used in studying bacterial-material interactions. Biomatter 2012;2(4):176-94. Crossref

13. Madigan MT, Martinko J, editors. Brock Biology of Microorganisms, 11th ed. Upper Saddle River, NJ, USA: Prentice Hall; 2006.

14. Arciola CR, Campoccia D, Montanaro L. Implant infections: adhesion, biofilm formation and immune evasion. Nat Rev Microbiol 2018;16(7):397-409. Crossref

15. Roach P, Eglin D, Rohde K, Perry CC. Modern biomaterials: a review - bulk properties and implications of surface modifications. J Mater Sci Mater Med 2007;18(7):1263-77. Crossref

16. Otto M. Staphylococcal Biofilms. Microbiol Spectr 2018;6(4). Crossref

17. Honda $M$, Kawanobe $\mathrm{Y}$, Ishii $\mathrm{K}$, Konishi $T$, Mizumoto $M$, Kanzawa N, Matsumoto M, Aizawa M. In vitro and in vivo antimicrobial properties of silver-containing hydroxyapatite prepared via ultrasonic spray pyrolysis route. Mater Sci Eng C Mater Biol Appl 2013;33(8):5008-18. Crossref 
18. Roy M, Fielding GA, Beyenal H, Bandyopadhyay A, Bose S. Mechanical, in vitro antimicrobial, and biological properties of plasma-sprayed silver-doped hydroxyapatite coating. ACS Appl Mater Interfaces 2012;4(3):1341-9. Crossref

19. Geng Z, Wang R, Zhuo X, Li Z, Huang Y, Ma L, Cui Z, Zhu S, Liang Y, Liu Y, Bao H, Li X, Huo Q, Liu Z, Yang X. Incorporation of silver and strontium in hydroxyapatite coating on titanium surface for enhanced antibacterial and biological properties. Mater Sci Eng C Mater Biol Appl 2017;71:852-61. Crossref

20. Lim PN, Shi Z, Neoh KG, Ho B, Tay BY, San Thian E. The effects of silver, silicon-containing apatite towards bacteria and cell responses. Biomed Mater 2014;9(1):015010. Crossref

21. Gómez-Barrena E, Esteban J, Medel F, Molina-Manso D, Ortiz-Pérez A, Cordero-Ampuero J, Puértolas JA. Bacterial adherence to separated modular components in joint prosthesis: a clinical study. J Orthop Res 2012;30(10):16349. Crossref

22. Neut D, Dijkstra RJB, Thompson JI, Kavanagh C, van der Mei $\mathrm{H}$, Busscher HJ. A biodegradable gentamicin-hydroxyapatitecoating for infection prophylaxis in cementless hip prostheses. Eur Cell Mater 2015;29:42-56. Crossref

23. Abdelnour SA, Abd El-Hack ME, Swelum AA, Perillo A, Losacco $C$. The vital roles of boron in animal health and production: A comprehensive review. J Trace Elem Med Biol 2018;50:296-304. Crossref

24. Boyacioglu O, Orenay-Boyacioglu S, Yildirim H, Korkmaz M. Boron intake, osteocalcin polymorphism and serum level in postmenopausal osteoporosis. J Trace Elem Med Biol 2018;48:52-6. Crossref
25. Sayin Z, Ucan US, Sakmanoglu A. Antibacterial and antibiofilm effects of boron on different bacteria. Biol Trace Elem Res 2016;173(1):241-6. Crossref

26. Yilmaz MT. Minimum inhibitory and minimum bactericidal concentrations of boron compounds against several bacterial strains. Turk J Med Sci 42(Sup 2):1423-9. Crossref

27. Cui $X$, Zhao C, Gu Y, Li L, Wang H, Huang W, Zhou N, Wang D, Zhu Y, Xu J, Luo S, Zhang C, Rahaman MN. A novel injectable borate bioactive glass cement for local delivery of vancomycin to cure osteomyelitis and regenerate bone. J Mater Sci Mater Med 2014;25(3):733-45. Crossref

28. Xie Z, Liu X, Jia W, Zhang C, Huang W, Wang J. Treatment of osteomyelitis and repair of bone defect by degradable bioactive borate glass releasing vancomycin. J Control Release 2009;139(2):118-26. Crossref

29. Güzel Y, Golge UH, Goksel F, Vural A, Akcay M, Elmas S, Turkon $\mathrm{H}$, Unver A. The efficacy of boric acid used to treat experimental Osteomyelitis caused by methicillin-resistant Staphylococcus aureus: an in vivo study. Biol Trace Elem Res 2016;173(2):384-9. Crossref

30. Jia W-T, Fu Q, Huang W-H, Zhang C-Q, Rahaman MN. Comparison of borate bioactive glass and calcium sulfate as implants for the local delivery of teicoplanin in the treatment of methicillin-resistant Staphylococcus aureusinduced osteomyelitis in a rabbit model. Antimicrob Agents Chemother 2015;59:7571-80. Crossref 